\title{
IMPROVED NEUROPROTECTION WITH MELATONIN-AUGMENTED HYPOTHERMIA VS HYPOTHERMIA ALONE IN A PERINATAL ASPHYXIA MODEL: A RANDOMIZED STUDY
}

\author{
E. Powell ${ }^{1}$, S. Faulkner ${ }^{1}$, A. Bainbridge ${ }^{2}$, A. Kereyni ${ }^{1}$, D. Kelen ${ }^{1}$, M. Chandrasekaran ${ }^{1}$, L. Lecky- \\ Thompson $^{1}$, D. Price ${ }^{2}$, E. Cady ${ }^{2}$, G. Raivich ${ }^{1}$, X. Golay ${ }^{3}$, N.J. Robertson ${ }^{1}$ \\ ${ }^{1}$ Institute for Women's Health, University College London, ${ }^{2}$ Medical Physics and Bioengineering, UCLH \\ NHS Foundation Trust, ${ }^{3}$ Institute of Neurology, University College London, London, UK
}

Background: Melatonin (N-acetyl-5-methoxytryptamine) is a naturally occurring hormone, anti-oxidant and cellular pro-survival factor, used safely in children with sleep disorders. Melatonin is beneficial following brain injury in adult animals. It is unknown if melatonin augments hypothermic neuroprotection in the developing brain.

Aims: To assess the neuroprotective efficacy of melatonin combined with cooling to $33.5^{\circ} \mathrm{C}$ in a piglet model of perinatal asphyxia.

Methods: Seventeen anaesthetised male piglets, $<24 \mathrm{~h}$ old, underwent transient hypoxia-ischaemia (HI), then were cooled to $33.5^{\circ} \mathrm{C} 2-26 \mathrm{~h}$ after $\mathrm{HI}$ and randomised to i) hypothermia alone $(\mathrm{n}=8)$; or ii) hypothermia + melatonin $(5 \mathrm{mg} / \mathrm{kg}$ infused over $6 \mathrm{~h}$ starting $10 \mathrm{~min}$ after $\mathrm{HI}$ and repeated at $24 \mathrm{~h}, \mathrm{n}=9)$. Cortical white matter $(\mathrm{WM})$ and ventromedial forebrain $(\mathrm{vmFB})$ proton $(1 \mathrm{H})$ and forebrain $(\mathrm{FB})$ were obtained at baseline, and 24 and $48 \mathrm{~h}$ following HI.

Results: Compared to hypothermia alone, melatonin and hypothermia significantly decreased the areas under the post $\mathrm{HI}$ time-series curves for vmFB lactate (Lac)/N-acetylaspartate(NAA) and Lac/creatine $(\mathrm{Cr})$ $(\mathrm{p}<0.05)$; as well as reducing the drop in WM NAA/Cr $(\mathrm{p}<0.05)$ (Fig1). Heart rate, mean arterial blood pressure and inotrope use did not differ between groups.

Conclusions: Validated MRS biomarkers suggested cooling plus melatonin augmented hypothermic neuroprotection in both $\mathrm{vmFB}$ and WM. Melatonin is a promising candidate for clinical trials of neuroprotection in the future.
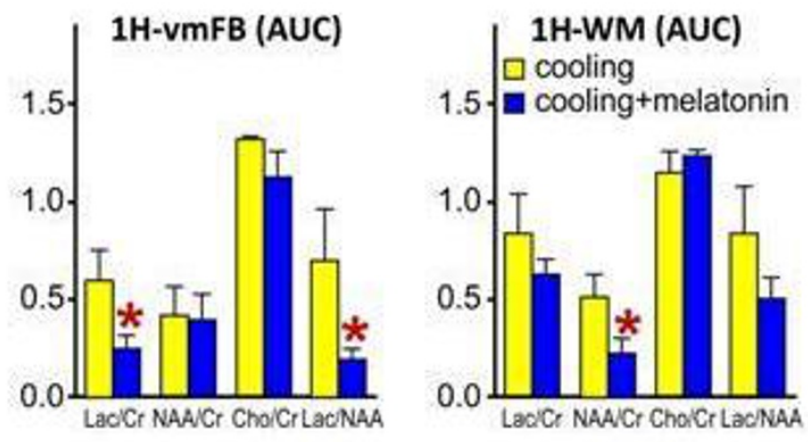

Fig 1: $\mathrm{VmFB}$ and $\mathrm{WM} 1 \mathrm{H}$ metabolite-ratio areas under the curves (AUC) $48 \mathrm{~h}$ post $\mathrm{HI}$. Yellow: cooling only; blue cooling plus melatonin. Cho - choline. ( ${ }^{*} p \leq 0.05$ two sided t-test)

[figure 1]

Funding: Wellbeing of Women, grant number RG952 